\title{
BIOQUÍMICA DA ESQUISTOSSOMOSE MANSÔNICA. VI - ALTERAÇÕES DO COMPARTIMENTO LISOSSÔMICO HEPÁTICO RELACIONADAS AO TEMPO DE INFECÇÃO
}

\author{
Luiz Erlon Rodrigues e Maria de Fátima Dias Costa
}

\begin{abstract}
O Schistosoma mansoni elou seus ovos causam uma hepatopatia muito importante e com aspectos anátomo-clínicos bem característicos. Uma vez carregados pela corrente circulatória, os vermes podem ocluir ramos dicotómicos de maior calibre do sistema portal e, quando mortos produzem lesões às vezes extensas, primeiro necróticas, depois inflamatórias e, posteriormente cicatriciais, sempre circunscritas e nâo sistematizadas. Os ovos, além de penetrarem nós ramúsculos não dicotômicos da rede periductal, alcançam os ramos de distribuiçâo ou até mesmo as vênulas aferentes, ocluindo muitas delas e, como conseqüência, formam os granulomas intravasculares que podem levar a uma interrupção da corrente sangüínea portal a esse nivel e alterações da circulação intralobular. A diminuição da taxa de oxigênio disponivel e conseqüentemente o decréscimo do pH intra e extracelular são potentes labilizadores das membranas dos diversos componentes do compartimento lisossômico. A saída de hidrolases ácidas, proteínas catiônicas e hidrolases neutras, a partir desses orgânulos, acarreta agressões tissulares muito importantes, com o desencadeamento e/ou manutenção dos processos inflamatórios típicos desta parasitose. Neste trabalho estudou-se as atividades lisossómicas ligadas às diversas fases da esquistossomose mansônica hepática. Os resultados indicaram que a integridade funcional dos complexos membranosos do compartimento lisossómico foi significativamente alterada, já a partir do segundo mês da infecção e que parece haver um estreito relacionamento entre o agravamento das lesões inflamatórias hepáticas com uma maior labilidade lisossômica.
\end{abstract}

Palavras chaves: Esquistossomose mansônica. Compartimento lisossômico hepático. Atividade lisossômica. Lisossomos.

A esquistossomose mansônica causa uma hepatopatia que, microscopicamente, exibe vários graus de lesões inflamatórias destrutivas e obstrutivas dos ramos do sistema porta intra-hepático, além de granulomas em torno de restos dos vermes e/ou ovos do Schistosoma mansoni 348122131 . Esses granulomas intravasculares podem levar a uma interrupção da corrente sangüinea portal e a alterações da circulação intralobular. Apesar disso, os hepatócitos, as células de Küpffer, os sinusóides e os lóbulos em geral não são atingidos diretamente pelo processo, porém sofrem suas conseqüências, decorrentes dos distúrbios da circulação portal ${ }^{21}$.

Freqüentemente, ao lado das lesões venosas, observa-se uma hipertrofia da artéria hepática, especialmente ao nivel do plexo peribiliar ${ }^{20}$. Para Andrade e Cheever ${ }^{5}$, essa arteriolização se acompanha de uma maior susceptibilidade do parênquima à queda da pressāo sistêmica, podendo levar à necrose focal isquêmica e à diminuição do gradiente de oxigênio entre a artéria hepática e a veia porta ${ }^{23}$.

Departamento de Biofunção/Setor de Bioquímica, Instituto de Ciências da Saúde, Universidade Federal da Bahia, 40000 Salvador, Bahia.

Recebido para publicação em 4/9/86.
A infiltração crônica por células mononucleares, que sempre se observa, parece estar ligada principalmente a causas imunológicas 2610152432 .

Das células polimorfonucleares, na fase aguda, e das mononucleares, na fase crônica da inflamação, foram isoladas várias substâncias e fatores flogogênicos, diretamente ligados aos lisossomos ${ }^{34}$. Dentre eles, destacam-se os mediadores vasoativos e ativadores desse sistema, os agentes quimiotáxicos, alguns dos quais são capazes de quebrar diversas frações dos complementos séricos, numerosos agentes enzimáticos com a capacidade de destruir a parede dos vasos e o tecido conjuntivo subjacente, além de ativadores da coagulação e da fibrinólise.

O potencial de mediadores da inflamação liberado a partir do complexo lisossômico, principalmente dos neutrófilos e de outras células envolvidas com os processos inflamatórios, inclusive plaquetas, é constituido, essencialmente, de hidrolases ácidas, proteinas catiônicas e hidrolases neutras ${ }^{19}$.

Todo esse conteúdo intralisossômico está preservado, em estado latente, por um complexo membranáceo cuja integridade físico-química é de extrema importância para a fisiologia celular.

De acordo com Fox e cols ${ }^{11}$, Kangilaski ${ }^{14}$ e Rodrigues e Galle ${ }^{27}$, vários agentes, dentre eles, a 
Rodrigues LE, Costa MFD. Bioquímica da esquistossomose mansônica. VI-Alterações do compartimento lisossômico hepático relacionadas ao tempo de infecção. Revista da Sociedade Brasileira de Medicina Tropical 20: 169-174, Jul-Set, 1987.

diminuição do pH intracelular, a diminuição da taxa de oxigênio disponível para os tecidos, certos cristais, exotoxinas, endotoxinas e complexos imunes, podem modificá-lo físico-quimicamente ou mesmo rompê-lo, permitindo a saída de componentes do conteúdo lisossômico e contribuindo para o desenvolvimento e/ou manutenção dos processos inflamatórios.

Diante do exposto, resolvemos estudar o envolvimento do compartimento lisossômico no desenvolvimento da lesão esquistossomótica, sobretudo no que diz respeito à físico-química de suas membranas e tentar relacionar as possiveis alterações das atividades lisossômicas com as diferentes fases evolutivas da esquistossomose mansônica hepática.

\section{MATERIAL E MÉTODO}

Foram utilizados dois grupos de camundongos albinos, de ambos os sexos, normalmente alimentados e constituidos de 20 animais para o controle e de 80 , para o grupo dos infectados. Os animais foram mantidos em gaiolas com no máximo 10 deles, sob condições semelhantes de umidade, temperatura, iluminação e ingestão hídrica.

A infecção dos camundongos, ainda jovens, pesando em média 18 gramas, foi feita com 100 cercárias, segundo a técnica descrita por Standen 30 e efetuada no Centro de Pesquisas Gonçalo Muniz (FIOCRUZ - Salvador). O principal controle da infeç̧ão foi realizado através de exames de fezes efetuados em todos os animais após 60 dias do início da mesma.

Todos os camundongos constituintes do grupo controle e do infectado, em diferentes periodos da infecção, com 45, 68, 82 e 100 dias, foram mortos por traumatismo craniano sem o emprego de anestesia. Seus fígados foram imediatamente retirados e colocados separadamente em solução tamponada de sacarose $25 \times 10^{-10} \mathrm{M}, \mathrm{pH} 7,4$ e entre $2^{\circ}$ a $4^{\circ} \mathrm{C}$. De cada um deles foi retirado um fragmento do lóbulo maior para a avaliação histológica do grau de infecção e, no caso dos figados controles, para a segurança de que os mesmos não estavam sujeitos a qualquer outro quadro nosológico.

Cada órgão, depois de separado da vesícula biliar, foi picotado na mesma solução e lavado diversas vezes para a retirada, ao máximo possível, do sangue. Em seguida, os fragmentos foram separadamente, ressuspensos na proporção de $1 / 10$, em nova solução tamponada a 7,4 e a $2^{\circ} \mathrm{C}$, especialmente adaptadas para a separação de orgânulos celulares por Voss e $\operatorname{cols}^{33}$ e homogeneizados em aparelho de PotterElvejhem, a $250 \mathrm{rpm}$, num tempo máximo de 2 minutos, em banho de gelo fundente.

A fração rica em lisossomos e partículas correlatas, correspondente a cada fígado, foi isolada por centrifugação fracionada e refrigerada a $2{ }^{\circ} \mathrm{C}$, no sedimento de $32.000 \mathrm{~g}$, durante 20 minutos, segundo a técnica proposta por Rodrigues e cols ${ }^{28}$. Este sedimento que concentra a maioria dos diversos componentes do compartimento lisossômico hepático, como por exemplo, vacúolos autofágicos, heterofágicos, autofagolisossomos, heterofagolisossomos, grânulos de secreção, lisossomos primários e corpúsculos residuais, foi utilizado como fonte das observações experimentais. Ele foi ressuspenso com a solução tampão especial para um volume igual àquele do homogeneizado inicial e incubado durante 20 minutos em banho de gelo. Após esse tempo, foi submetido a uma nova centrifugação a $32.000 \mathrm{~g}$, durante 20 minutos, para a separação, num novo sedimento dos lisossomos intactos e das membranas daqueles que foram lisadas durante o tempo de incubação.

A determinação da atividade lisossômica neste último sobrenadante permite a avaliação das condições físico-químicas relacionadas com uma maior ou menor estabilidade das membranas lisossômicas, ligadas às diversas fases evolutivas da esquistossomose mansônica hepática.

Esta atividade foi avaliada através da ortofosfórico mono ester fosfohidrolase, 3.1.3.2. (fosfatase ácida), segundo a técnica proposta por Andersh e Szcypinski ${ }^{1}$, usando o p-nitro fenilfosfato como substrato. As dosagens das proteínas totais foram efetuadas através a técnica de Lowry e cols ${ }^{16}$.

Sendo os lisossomos e partículas correlatas, orgânulos muito frágeis, podem apresentar modificações físico-quimicas algumas vezes severas, chegando mesmo à lise de suas membranas, com a conseqüente liberação dos seus conteúdos enzimáticos, quando submetidos às variadas condições experimentais. Portanto, cada experiència controle foi processada em dobro, usando-se numa delas, a digitonina $10 \mathrm{mM}$. As próprias condições de isolamento e de experimentação podem contribuir para a lise lisossômica. Somente aquelas experiências, onde o efeito lisante, causado pela digitonina, alcançou cinco vezes a atividade do controle, foram consideradas ideais ${ }^{26}$.

\section{RESULTADOS}

A integridade funcional das membranas dos diversos componentes do compartimento lisossômico pode ser avaliada através da medida da atividade da enzima fosfatase ácida, sempre presente no interior dessas partículas. A saída dessa hidrolase para o meio externo é um indicador bioquímico, dos mais seguros, no que tange à estabilidade das membranas lisossômicas.

A atividade controle, obtida de lisossomos isolados de fígado de animais não submetidos a infecção esquistossomótica, foi de $11,6 \pm 2,5 \mathrm{mUI}$ por miligrama de proteinas totais, em termos de fosfatase ácida. 
Rodrigues LE, Costa MFD. Bioquímica da esquistossomose mansônica. VI-Alteraçóes do compartimento lisossômico hepático relacionadas ao tempo de infeção. Revista da Sociedade Brasileira de Medicina Tropical 20: 169-174, Jul-Set, 1987.

Os animais infectados mostraram atividades sempre maiores quando comparadas com os controles. Da observação da Figura 1, depreende-se que os aumentos das atividades lisossômicas hepáticas, observados nos diferentes periodos examinados da infecçāo esquistossomótica, se fazem de maneira marcadamente ligada ao estágio da lesão hepática examinada.

\section{EFEITO LITICO DA DIGITONINA SO- BRE A ATIVIDADE LISOSSÔMICA EM FIGADOS DE CAMUNDONGOS CON- TROLES.}

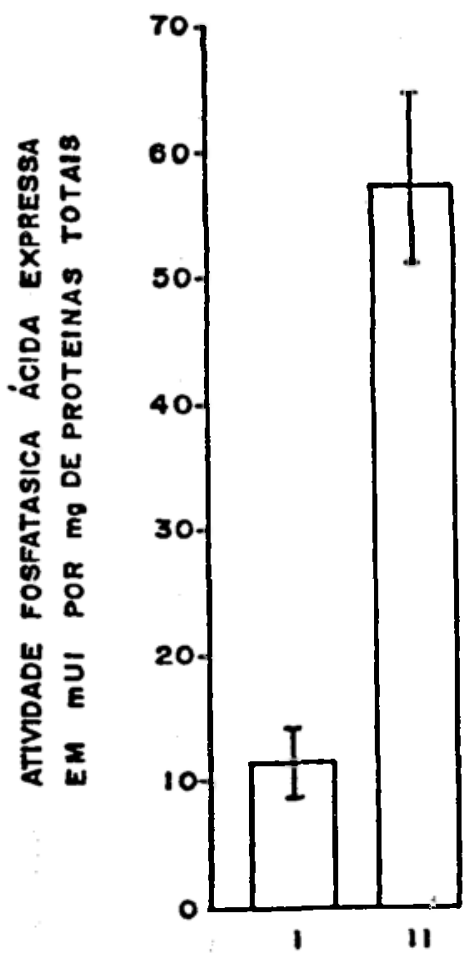

\section{1 - LISOSSOMOS CONTROLES \\ " - tratados PEla digitonina $10 \mathrm{~mm}$}

\section{Fig. 1}

A atividade fosfatásica ácida, representativa do compartimento lisossômico isolado de figados de camundongos infectados com 45 dias, foram de $13,3 \pm 3,8 \mathrm{mUI} / \mathrm{mg}$. Comparada com aquela obtida dos controles, este aumento não apresentou, contudo significância estatística. No entanto, todos os outros resultados obtidos a partir dos 68 dias foram estatisticamente significantes, $\mathrm{p}<0,05$ para 68 dias, e $\mathrm{p}<0,01$ para 82 e 100 dias.

A atividade enzimática observada no período de 68 dias, $17,2 \pm 3,3 \mathrm{mUI} / \mathrm{mg}$, foi $48 \%$ maior que a dos controles. As correspondentes aos 82. e $100 \%$ dias foi de $24,2 \pm 5,4$ e $38,4 \pm 8,4 \mathrm{mUI} / \mathrm{mg}$, portanto 109 e
$231 \%$ respectivamente maiores que aquela encontrada no compartimento lisossômico, isolado de fígados de animais não infectados.

No sentido de avaliar os métodos de isolamento e de experimentação empregados e relacionados com o compartimento lisossômico foi efetuada a prova da digitonina sobre as experiências controles.

Observa-se, na Figura 2 que os lisossomos isolados de figado de animais não infectados, tratados pela digitonina $10 \mathrm{mM}$, apresentaram uma atividade especifica igual a $58,4 \pm 7,4 \mathrm{mUI} / \mathrm{mg}$. Isto corresponde a cinco vezes a atividade encontrada nos lisossomos não tratados por esta substância.
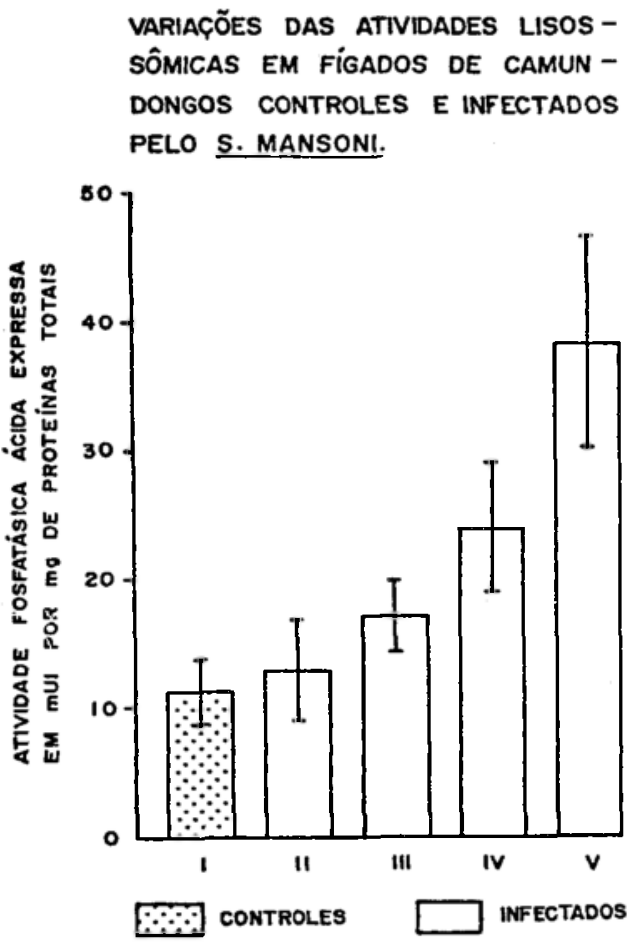

1 - CONTROLES

" - COM 45 DIAS DE INFECÇÃO

III - COM 68 DIAS DE INFECÇÃO

IV - COM 82 DIAS DE INFECÇÄO

$\checkmark$ - COM 100 DIAS DE INFECÇÃO

Fig. 2

$\mathrm{Na}$ concentração final empregada de $10 \mathrm{mM}$ a digitonina é capaz, segundo Rodrigues e $\operatorname{cols}^{26}$, de lisar integralmente os lisossomos e partículas a eles correlacionadas, durante o tempo de 20 minutos usado na incubação. Este dado é muito importante porque permite calcular a atividade lisossômica total em 
Rodrigues LE, Costa MFD. Bioquímica da esquistossomose mansônica. VI-Alteraçôes do compartimento lisossômico hepático relacionadas ao tempo de infeç̧ão. Revista da Sociedade Brasileira de Medicina Tropical 20: 169-174, Jul-Set, 1987.

determinadas condições de experimentação. Diante do exposto, todas as experiências cujos controles apresentaram atividade fosfatásica ácida superior a $20 \%$ em relação àquela obtida pela lise total provocada pela digitonina, não foram aproveitadas. Consideramse como normais as condições de experimentação que instabilizam em menos de $20 \%$ as membranas dos componentes do compartimento lisossômico.

A comparação entre as atividades lisossômicas, obtidas para as diversas fases estudadas, da esquistossomose mansônica hepática, com aquela relativa à lise total dos lisossomosos, $58,4 \pm 7,4 \mathrm{mUI} / \mathrm{mg}$, mostra que, com 45 dias, as condições utilizadas no isolamento e manipulação dessas particulas são capazes de lisar $23 \%$ das mesmas. Com 68 dias, este índice de lise aumenta para $29 \%$. Aos 82 e 100 dias, ele atinge, respectivamente, 41 e $66 \%$. Isto demonstra claramente que, dentro dos limites das condiçōes de experimentação empregados, as membranas dos diversos componentes do compartimento lisossômico são tornadas mais frágeis, à medida que evoluem as manifestações hepáticas na esquistossomose mansônica.

\section{DISCUSSÃO}

O grupo de animais com 45 dias de infeç̧ão foi incluido nas observações experimentais, baseado em dois fatos determinantes. Primeiramente Brener ${ }^{9}$ observou a presença, nas veias mesentéricas do camundongo infectado pelo $S$. mansoni, de vermes adultos e acasalados, prontos para a postura de ovos, após o trigésimo quarto dia. Secundariamente, Rodrigues e cols ${ }^{28}$ demonstraram que o comportamento bioquimico de fígado de camundongos, infectados com 100 cercárias e com até 30 dias de infecção, apesar de ainda não ter sido neles detectada a presença de granulomas, causados por vermes ou ovos do parasito nos animais usados nas suas experimentaçōes, se caracterizava, em termos de atividades respiratórias mitocondriais, bastante estimulado, quando comparado com as observações controles. Este grupo de camundongos, infectados por 100 cercárias e com 45 dias de infecção representa, portanto, o início do envolvimento hepático na esquistossomose mansônica experimental, nesses animais e, se constituiu, no único grupo onde o controle da infecção não foi realizado através do exame de fezes, feito após o $600^{\circ}$ dia. Este controle foi, contudo, efetuado através do estudo histológico de fragmentos hepáticos.

A atividade lisossômica medida em termos de fosfatase ácida e que representa, de modo indireto, mas bastante preciso, as condições físico-químicas de estabilidade da membrana desses orgânulos, apresentou-se significantemente aumentada no fígado dos animais infectados pelo $S$. mansoni. Este aumento foi cada vez maior, à medida que as análises eram feitas nos diferentes grupos de animais infectados. Pode-se concluir, baseado nos resultados da parte experimental que, bem provavelmente, a membrana dos lisossomos, assim como a das outras partículas a eles relacionadas, tornava-se mais lábil na dependência da infecção esquistossomótica. $\mathrm{O}$ aumento da atividade fosfatásica ácida talvez não se deva, como demonstraram Rodrigues e Soares ${ }^{29}$, ao aumento do número de lisossomos decorrentes da infiltração inflamatória estabelecida. Isto porque os resultados que exprimem as atividades lisossômicas são expressos em valores específicos, por sua vez obtidos a partir daqueles que expressam as atividades absolutas, relacionados com as proteínas de cada amostra.

O aumento da labilidade da membrana dos componentes do complexo lisossômico pode ser motivado por vários fatores que, no caso específico da esquistossomose mansônica, parecem ligados à presença de substâncias catabólicas liberadas pelo verme e/ou pelo ovo do parasita, ou ainda pelo menor aporte de oxigênio dissolvido, decorrente do infiltrado inflamatório que se estabelece como também, possivelmente, pela obliteração dos sinusóides hepáticos pelo parasitismo.

Vários mecanismos tentam explicar as variaçōes de estabilidade por que passam as diversas membranas do compartimento lisossômico, quando submetidas aos mais diferentes estímulos físicos, químicos $\mathrm{e}$ biológicos. Obviamente, nenhum dos mecanismos propostos explica, integralmente, os fenômenos de estabilização por que passam as membranas lisossômicas. $\mathrm{Na}$ realidade, muitas são as causas que determinam as variações de estabilidade. Raz e Goldman $^{22}$ sugeriram que $o$ aumento na permeabilidade das membranas do compartimento lisossômico envolve fenômenos osmóticos os quais promovem a entrada de substâncias de baixo peso molecular para o interior dessas partículas. Isto explicaria o aumento da pinocitose de lipidios de baixo peso molecular, especialmente ácidos gordurosos não esterificados e triglicerídios, pelos lisossomos, nos periodos iniciais do envolvimento hepático na esquistossomose mansônica.

Muitas das substẩncias que atuam modificando a estabilidade das membranas interagem com os fosfolipidios constitutivos. Segundo Blohm 7 , apesar dessas substâncias pertencerem a tipos farmacológicos extremamente diversos, elas têm natureza química comum que as fazem capazes de reagir com os fosfolipídios. Todas são bases fracas que se ionizam por protonação, possuem grupos hidrofóbicos e, usualmente, tem um ou mais núcleos aromáticos. Estes compostos são descritos como anfifilicos ou anfipáticos, mais especificamente catoanfifilicos, justamente porque se protonizam. As moléculas anfifilicas aniônicas não apresentam a propriedade de interagirem com os fosfolipidios constituintes das 
Rodrigues LE, Costa MFD. Bioquimica da esquistossomose mansônica. VI-Alteraf̧ões do compartimento lisossômico hepático relacionadas ao tempo de infeção. Revista da Sociedade Brasileira de Medicina Tropical 20: 169-174, Jul-Set, 1987.

membranas. Os termos anfifílico e anfipático se re ferem à dupla afinidade que essas moléculas possuem; todas têm um polo hidrofilico, caracterizada pelo grupamento básico ionizado e outro lipofilico, representado pela porção de hidrocarboneto apolar.

Lullmann e cols ${ }^{17}$ propuseram que tais moléculas anfifilicas, no estado de grupamento básico não ionizado podem facilmente passar através das membranas biológicas e formarem pares iônicos complexos, com fosfolipídios. Estes complexos formados pela interação entre determinadas drogas e os fosfolipidios constituintes das membranas podem ocacionalmente torná-las resistentes à degradação normal pelas enzimas lisossômicas. Isto explicaria o acúmulo e a concentração de certas substâncias pelos lisossomos, notadamente os metais pesados.

A cloroquina se constitui num dos modelos de substâncias lisossomotrópicas mais estudadas, porque se trata de um exemplo de base fraca suficientemente lipofilica para penetrar através a membrana plasmática até o citossol, onde é captada por protonação dentro dos lisossomos. Ela e outras drogas antimaláricas são portanto concentradas pelos lisossomos de animais superiores tanto "in vivo" quanto "in vitro" como demonstraram Mego e Chung18. Além deste fato, essa droga tem sido usada como excelente inibidor da catepsina B, a mais importante protease lisossômica. Compreende-se, então, porque a cloroquina é capaz de ser concentrada pelos eritrócitos parasitados pelos diferentes plasmódios, a níveis muitas vezes maiores que os encontrados no plasma.

Apesar dos fosfolipidios serem extremamente importantes na manutenção da função e da estabilidade dos complexos de membranas, os outros componentes lipídicos, a exemplo do colesterol, seus ésteres, ácidos graxos livres e triacilglicerois, podem também contribuir de maneira decisiva para estas finalidades.

A digitonina, glicosidio extremamente utilizada experimentalmente como lisante de membrana lisossômica, tem este efeito explicado porque se combina com o colesterol livre das mesmas, formando um complexo que não permite a interação fisiológica entre esta substância e os fosfolipidios, resultando daí uma desestabilização brusca das membranas, terminando sempre na lise das mesmas.

O envolvimento do retículo endoplasmático dos hepatócitos em animais portadores da esquistossomose mansônica, salientado recentemente por Rodrigues $^{25}$, pode contribuir para o aumento geral de lipidios, não só citoplasmáticos como também dos lisossomos. Os intercâmbios que se verificam entre essas diversas substâncias, componentes das membranas lisossômicas, de um lado, e os altos teores das mesmas presentes no citoplasma ou no interior daqueles orgânulos, do outro, podem contribuir para desestabilização desses complexos de membranas. $O$ aumento da labilidade das membranas lisossômicas pode ser acompanhado pela liberação de enzimas hidroliticas e, conseqüentemente, de ataque de componentes importantes para a fisiologia celular. A própria membrana plasmática pode ser lisada por essas enzimas o que acarretará a morte celular, com o extravasamento dessas mesmas hidrolases para o meio externo, iniciando ou mantendo, desse modo, o processo inflamatório característico dessa parasitose.

Finalmente, a liberação do conteúdo dos diversos componentes do compartimento lisossômico, a partir, principalmente, das células do infiltrado inflamatório, pelos mecanismos de regurgitação durante a fagocitose e de endocitose reversa, descritos por Honing e cols ${ }^{13}$, possivelmente desempenham papel muito importante no desencadeamento e/ou manutenção das lesões inflamatórias, ligadas aos complexos imunes na esquistossomose mansônica.

\section{SUMMARY}

Schistosoma mansoni and/or its eggs cause important hepatic pathology distinguished by very characteristic anatomo-clinical features. If carried by the blood stream, the worms are able to occlude dichotomic branches of larger diameter of the portal system. These worms, when dead, produce lesions that are sometimes extensive, initially necrotic, then inflammatory and finally cicatricial. These lesions are always circumscribed and not systematized. Besides penetrating into the tiny non-dichotomic branches of the periductal net, the eggs reach the branches of distribution or even the afferent venulae, occluding some of them. Consequently intravascular granulomas are formed which can lead to an interruption of the portal blood stream at this level and to changes in the intralobular circulation. The decrease of the rate of available oxygen and consequent decrease in the intra and extracellular $\mathrm{pH}$ are potent labilisers of membranes of several components of the lysosomal compartment. The exit of acid hydrolases, cationic proteins and neutral hydrolases from these organelles brings about major tissular aggression, represented by the formation and maintenance of the typical inflammatory processes of this parasitism. In this work lysosomal activity related to hepatic schistosomiasis mansoni has been studied. The results indicated that the functional integrity of the lysosomal membrane complexe had been significantly changed. These changes have been observed from the second month of infection and there seems to be a close relationship between the severity of the liver inflammatory lesions and a greater lysosomal lability.

Key words: Schistosomiasis mansoni. Hepatic lysosomal compartment. Lysosomal activity. 


\section{REFEREANCIAS BIBLIOGRÁFICAS}

1. Andersh MA, Szcypinsky AJ. Use of p-nitrophenylphosphate as the substrate in the determination of serum acid phosphatase. The American Journal of Clinical Pathology 17:571-574, 1947.

2. Andrade ZA. Imunopatologia. In: Cunha AS (ed) Esquistossomose mansoni. Sarvier e Editora da USP, São Paulo, p. 61-75, 1970.

3. Andrade ZA. O fígado esquistossomótico. Arquivos Catarinenses de Medicina 13:53-57, 1984.

4. Andrade ZA, Bina JC. A patologia da forma hépatoesplênica da esquistossomose mansoni em sua forma avançada (Estudos de 232 necrópsias completas). Memórias do Instituto Oswaldo Cruz 78:285-305, 1983.

5. Andrade ZA, Cheever AW. Alterations in the intrahepatic vasculature in hepatosplenic schistosomiasis mansoni. American Joumal of Tropical Medicine and Hygiene 20:425-432, 1971

6. Andrade ZA, Paronetto F, Popper H. Immunocytochemical studies in schistosomiasis. The American Journal of Pathology 39:589-598, 1961.

7. Blohm TR. Drug-induced lysosomal lipidosis: Biochemical interpretations. Pharmacological Reviews 30:593$603,1979$.

8. Bogliolo L. Sobre o quadro anatômico do fígado na forma hépato-esplênica da esquistossomose mansônica. O Hospital 45:283-306, 1954.

9. Brener Z. Observações sobre a infecçāo do camundongo pelo Schistosoma mansoni. Revista Brasileira de Malariologia e Doenças Tropicais 8:565-575, 1956.

10. Coker CM, Von Lichtenberg F. A revised method for isolation of $S$. mansoni eggs for biological experimentation. Proceedings of the Society of Experimental Biology and Medicine 92:780, 1956.

11. Fox AC, Hoffstein S, Weissman G. Lysosomal mechanisms in production of tissue damage during myocardial ischemia and the effect of treatment with steroids. The American Heart Journal 91:394-387, 1976.

12. Hashem M. The aetiology and pathogenesis of the endemic form of the hepato-esplenomegaly "Egyptian splenomegaly". The Journal of Royal Egypt Medical Association 30:48-79, 1947.

13. Honing S. Hoffstein S, Weissmann S. Leucocyte lysosomes and inflammation: the example of arthritis. Pathobiology Annual 8:315-331, 1978.

14. Kangliaski J. Secrets of inflammation only partly revealed. Medical News 246:2543-2544, 1981.

15. Litt M. Eosinophils and antigen-antibody reactions. Annals of the New York Academy of Sciences 116:964$985,1964$.

16. Lowry OH, Rosenbrough NJ, Farr AL, Randall RJ. Protein measurement with Folin phenol reagent. The Journal of Biological Chemistry 193:265-275, 1951.

17. Lullmann H, Lullmann-Rauch R, Wassermann O. Druginduced phospholipidosis. CRC Critical Review on Toxicology 4:185-218, 1975.

18. Mego JL, Chung CH. Effects of some antimalarials and related substances on intra lysosomal proteolysis. Biochemical Pharmacology 28:465-470, 1979.
19. Ranavide NS, Cochrane CG. Basic proteins in rat neutrophil that increase vascular permeability. Clinical and Experimental Immunology 6:905-911, 1970.

20. Raso P. Lesões vasculares intra-hepáticas na forma hépato-esplênica da esquistossomose mansônica. $\mathrm{O}$ Hospital 52:517-550, 1957.

21. Raso P, Bogliolo L. Patologia. In: Cunha AS (ed.) Esquistossomose mansoni. Sarvier e Editora da USP, São Paulo, p. 78-130, 1970.

22. Raz A, Goldman R. Differential effects of lipids on the osmotic fragility of lysosomes. Experientia 32:447-449, 1967.

23. Ribeiro JPA. O gradiente de oxigênio e o fluxo sangüíneo hepático na esquistossomose mansônica hépato-esplènica, forma de Symmers. Revista da Associação Médica Brasileira 13:442-445, 1967.

24. Rocha H. Glomerulopatia da esquistossomose mansônica. In: Azevedo ES, Rebouças G, Rocha H, Lyra LGC, Teixeira RS, Andrade SG, Andrade ZA (eds). Aspectos peculiares da infecção pós Schistosoma mansoni. Centro Editorial da UFBA, p. 133-160, 1984.

25. Rodrigues LE. Alterações bioquímicas lisossômicas na esquistossomose mansônica hepática experimental. Tese de Titular, Universidade Federal da Bahia, 1984

26. Rodrigues LE, Costa MFD, Batista P. Biochemistry of Schistosomiasis mansoni. IV - Effects of oxamniquine on the hepatic lysosomal activity. Revista do Instituto de Medicina Tropical de São Paulo 25:223-228, 1983.

27. Rodrigues LE, Galle P. Lysosomotropisme et action antiinflammatoire des sels d'or. Revue du Rhumatisme 52:479-483, 198 j.

28. Rodrigues LE, Oliveira UR, Gaudenzi TF. Estudo bioquímico da esquistossomose mansônica hepática. I Relaçāo hospedeiro - parasito na infecção experimental do camundongo. Gazeta Médica da Bahia 68:61-69, 1968.

29. Rodrigues LE, Soares MCM. Estudo da labilidade da membrana dos lisossomos na infecçāo experimental pelo S. mansoni. II - Observações em figados infectados. Revista Brasileira de Pesquisas Médicas e Biológicas 7:175-181, 1974.

30. Standen OD. The penetration of cercarie of Schistosoma mansoni into the skin and lymphatics of the mouse. Transactions of the Royal Society of Tropical Medicine and Hygiene 42:292-298, 1953.

31. Symmers WStC. Note on a new form of liver cirrhosis due to the presence of the ova of Bilharzia Hematobia. Journal of Pathology and Bacteriology 9:237-239, 1904.

32. Von Lichtenberg F, Sadum EH, Cheever AW, Erickson DG, Johnson AJ, Boyce HW. Experimental infection with Schistosoma japonicum in chimpanzees. Parasitologic, clinical, serologic and pathological observations. American Journal of Tropical Medicine and Hygiene 20:850-893, 1971

33. Voss DO, Cowles JC, Bacila M. A new oxygen electrode model for the polarographic assay of cellular and mitocondrial respiration. Analytical Biochemistry 6:211222, 1963.

34. Willoughby DA. Inflammation. Endeavour 2:57-65, 1978. 